\title{
Does gender matter in online learning?
}

\author{
Mae McSporran and Stuart Young \\ Department of Information Systems and Computing, UNITEC Institute of Technology, \\ Auckland, New Zealand \\ email: mmcsporran@unitec.ac.nz
}

It is generally noted that computing is gendered, with women opting out of IT. Will the impact of online learning change this? Some researchers claim that women are disadvantaged in online courses. Others argue that we need a "women-friendly cyberclassroom'. Yet our experience is that the women achieve better results than the men; it is loner males that are disadvantaged by distance learning. We argue that online courses need to be people-friendly so that no learners are disadvantaged.

Internet and Web Design is a popular first-year introductory course in the Bachelor of Computing Systems degree. Since 1999 it has been taught flexibly. As well as traditional classroom sessions, we offered our students the choice of working remotely. Students could access the self-assessment questions and course notes and exercises in the classroom sessions or off site at any time of day or night. The option of online learning proved to be very popular with the students, particularly those with work and family commitments.

Our research uses pre-and post-course questionnaires and focus groups, and includes the assessment results and behaviour of the different demographic groups of students. We considered such issues as student motivation, preferred study methods, personal commitments, access to technology and support methods.

We found that our course favours women and older students, who seem to be more motivated, better at communicating online and at scheduling their learning. In contrast, male students and younger participants need the discipline that classroom sessions provide. Interestingly, our course has a larger proportion of female students than the degree programme as a whole. The challenge now perhaps is to encourage loner male 'nerds' ${ }^{1}$ to succeed online.

\section{Introduction}

The image of a stereotypical computing student is still 'geeky' (Selby, Ryba and Young, 1997; Margolis, Fisher and Miller, 1999) or 'nerdy, unwashed and working incredibly long 
hours, pausing occasionally to drink coke and order a pizza' (Brook, Mann and Virtue, 2000 ). This might be the reason that only 20 per cent of undergraduate IT students are female (Brook et al., 2000). Indeed over the years there have been many attempts to be proactive and promote women in IT, both by institutes and individuals. ${ }^{2}$

Many researchers have reported that women are disadvantaged in the computing classroom. Dale Spender (1995: 176) quotes Cole et al. (1994) as saying males 'dominate the class rooms and male priorities have shaped the subject's image'. Spender feels that the computer classroom is so threatening and abusive to women that she compares it to the playing field, whilst admitting like Griffiths (1985) that the research on girls focuses on 'issues of tension and exclusion' and presents a deficit model (Spender, 1995: 233).

In the first half of the 1990s researchers also reported that this 'locker room' atmosphere extended to online discussions (Kramarae and Taylor, 1993). Males behaved aggressively and hogged conversational space (Currie, 1993; Spender, 1995: 194). Tales of 'online violence and harassment', and even stalking predominated (Bell and de La Rue, 1995). Indeed even in female-orientated newsgroups, almost 70 per cent of respondents were male (We, 1993). Kramarae and Taylor (1993) comment: 'So many men are querying, correcting and attacking the terms and priorities of these women-organised bulletin boards that many women have complained that the climate is too hostile for them and they have withdrawn as subscribers.' However, this may be because in the early 1990s the Internet population was predominately male, and the software tools needed to access the Internet usually required the use of arcane text-only commands.

Some researchers claim that this situation continues. Blum (1999) describes males dominating an online educational discussion forum, abusing women with negative comments about their computing and technical knowledge, causing the women to stop using the discussion forum and leave the cyber-classroom. Others argue that we need 'women friendly cyber-classrooms' (Richardson and French, 1999). However the situation is changing rapidly. eMarketer report a Media Matrix study that in January 1999, for the first time, women made up half of all US adult Internet users. With more women online, resulting in more women using online learning, male voices should no longer dominate.

There is also disagreement whether the Net is suitable to the learning styles of female students. Anderson (1997) suggests that female learners have a marked preference for faceto-face communication. Belanger (1999) emphasizes that whilst there is still a lower rate of female participation on the Internet, the Net may prove more suitable to the learning style of females. Even more interestingly, a Canadian study of the use of computer communications for learning reported that 81 per cent of the women reported a positive experience compared with 77 per cent of the men. ${ }^{3}$

At this time many tertiary institutions are experimenting with online learning (Bates, 1995). Many of the courses offered use 'course building shells' which allow content experts to design a course with minimum technical knowledge (e.g. WebCT, Blackboard CourseInfo). Blackboard administrator John Simmons reported that the system has 300,000 registered students and according to their Website, WebCT has 6.9 million students in 1,494 institutions in 57 countries. Both companies are also experimenting with 'brokering' and promoting well-designed pre-packaged courses to be taught online. With the trend towards 'life-long learning' there is an increase in self-study online as well as 
institutional credited courses. Belanger (1999) reports that in 199821.6 per cent of Internet users used the Internet for distance education.

Many papers have been written about the problems faculty members face in this new learning environment. If technological and teaching style changes prove challenging for the teachers, what about the students? Should we be concerned whom this computersupported learning community best suits? Who learns best online and which group adapts best to this method and media? Students pay course fees but may not have the skill set to 'learn online'. Should we be warning them that they might not have the attitude or aptitude required, or just take their money? According to Bates (1999: 11) course providers should 'identify key target groups and markets for online, multimedia education and training; develop programming for which there is a well defined market, both in the private and public sectors'. Should we also profile which students engage cognitively with online learning and which do not? Is online delivery best used for discussion and communicationrich courses rather than practical subjects?

While the move to online learning is mainly a response to the changing needs of students, institutions also expect that teaching online will save time, cut costs and earn revenue. Learning off site within a virtual 'learning community' is touted as convenient, cheaper and useful (Richie, 1997; Trinkle, 1999). Leaving aside the question of whether this is true or not, the trend to online learning may have the side effect of benefiting learners who feel intimidated in the classroom. Our experience is that the women achieve better results than men do; it is the loner males who are disadvantaged by distance learning (e.g. Young, Dewstow and McSporran, 1999). We will argue that online courses need to be peoplefriendly so that no learners are disadvantaged.

\section{About the course}

Internet and Web Design (IWD) is a popular first-year introductory course in the Bachelor of Computing Systems degree. Students with a wide range of ages, ethnic backgrounds, life and work experiences study it. At first it was taught by traditional means of lectures and practical classroom sessions. Then in the first semester of 1999 we changed to a more flexible method of teaching (Young et al., 1999). As well as classroom sessions, we offered our students the choice of working remotely - that is, working through the lecture notes, practical exercises and weekly formative self-assessment questions online. Students could access the Website in the practical sessions or off site at any time of day or night. If they had a problem they could attend a classroom session or use electronic communication to seek specific help. The option of this flexible learning format proved to be very popular with the students.

In the 1999-2000 summer school, the course was offered completely remotely (Dewstow, Young and McSporran, 2000). There were no face-to-face (F2F) sessions except an introductory session, the project presentations and final exam. If students had problems, they had to seek help electronically. They were requested to post their question on the bulletin board rather than use email. This avoided duplication of lecturer responses; attempted to mirror classroom communication by allowing students to answer each other's questions; provided students with experience of Web-based discussions; and tested the suitability of bulletin boards for online courses. 
The IWD course is assessed by means of a group research report, an individual practical exercise (production of a ten-page Website) and a written exam. Part of the group research report mark is attributed to electronic communication. There have been no changes to the method of assessment across the semesters so we are able to compare results from students who studied in class with those who studied completely online and those who studied online but had the option of F2F contact.

\section{Study methodology}

Data for the study were collected in three ways.

1. Pre- and post-course surveys: This study is part of an ongoing program of research using pre- and post-course questionnaires, which seek both qualitative and quantitative answers. On the first day of the course the students are asked to fill out a questionnaire, from which we gather information on their ethnic background, age, gender, previous education and Internet experience, and asked them to choose whether they would study online or in traditional classroom sessions. At the end of the course the students complete another survey which determined their actual method of course participation, and also gathered their comments about the experience of online learning. Students scored items on a five-point Likert scale, ranging from 1 'strongly disagree' to 5 'strongly agree'. For continuity, the summer school questionnaires used the same questions as previous semesters, but additional questions relevant to the unique situation of the summer school were added.

2. Student assessment results: There were student results from both formative and summative assessments completed during the course. The results from the different groups were compared.

3. Focus groups: In 1999 students who studied entirely online were invited to a post-course focus group, where their thoughts and experiences of online learning were discovered. In Semester 1, 1999, this was conducted by Dr Cathy Gunn of Auckland University, while in Semester 2, 1999, it was conducted by Claire Donald of UNITEC.

There is a difference between the total number of pre- and post-questionnaire responses for each semester. Reasons for this include student drop-outs, non-attendance at the project presentation sessions when the post-questionnaire is filled out and students not filling in their names on the questionnaire. In Semester 1, 1999, there were 71 first questionnaires and 54 matched second questionnaires. In Semester 2, 1999, there were 90 first questionnaires and 63 matched second questionnaires. In the summer school, 1999-2000, there were 27 first questionnaires and 19 matched second questionnaires. In Semester 1, 2000 , there were 88 first questionnaires and 68 matched second questionnaires.

\section{Results}

\section{Gender of students studying IWD}

More women study IWD than other computing courses in the degree as shown in Table 1. This discrepancy could result from students from other degree programmes studying our course, people working on full-time study of IWD as a Certificate of Proficiency (COP), or 
just that it is more popular with women within the degree than, for example, programming or network courses.

\begin{tabular}{lrrrr}
\hline Semester & \multicolumn{2}{c}{ Female } & \multicolumn{3}{c}{ Male } \\
& no. & (\%) & no. & (\%) \\
\hline Semester 1, 1999 & 21 & 29.6 & 50 & 70.4 \\
Semester 2, 1999 & 32 & 36.0 & 57 & 64.0 \\
Summer School, 1999-2000 & 7 & 28.0 & 18 & 72.0 \\
Semester 1, 2000 & 23 & 26.1 & 65 & 73.9 \\
BCS Degree average 1999 & & 23.0 & & 77.0 \\
\hline
\end{tabular}

Table 1: Gender of students studying IWD 1999-2000

The popularity of IWD among women is presumably due to the nature of the course: it involves a great deal of interpersonal and visual communication and it is currently a very popular and highly hyped subject. Anecdotal and focus group evidence points to the female students thinking ahead to the workplace. They see Web-page design as an opportunity for home-based or part-time employment. Margolis et al. (1999) describe this concept as 'computing for a purpose'. The possibility of contract and part-time work and working from home is highly featured in an Australian Information Industry Association report ('Women in Information Technology'). Also promoted is 'job sharing' and meshing family responsibilities with work.

\section{Gender differences in the choice of working remotely or in class}

There was a consistent difference between the sexes as shown in Table 2. Between 52 and 62 per cent of the women taking IWD chose to work in class compared with 63-80 per cent of the men. The men were also more uncertain - the men were more likely to say maybe, whereas the women were more definite that they wanted to work online.

\begin{tabular}{lrrrrrr}
\hline Semester & Class & $\begin{array}{c}\text { Female (\%) } \\
\text { Remote }\end{array}$ & Maybe & Class & $\begin{array}{c}\text { Male (\%) } \\
\text { Remote }\end{array}$ & Maybe \\
\hline Sernester 1,1999 & 57.1 & 38.1 & 4.8 & 80.0 & 10.0 & 10.0 \\
Semester 2,1999 & 62.5 & 31.3 & 6.3 & 63.2 & 26.3 & 10.5 \\
Summer School, 1999-2000 & - & 100.0 & - & - & 100.0 & - \\
Semester 1,2000 & 52.2 & 39.1 & 8.7 & 64.6 & 27.7 & 7.7 \\
\hline
\end{tabular}

Table 2: Gender differences in the choice of working remotely or in closs

As stated above, the higher popularity of studying remotely among women could be due to a number of factors. The women may have family and work commitments making travelling to campus more costly in time as well as financially. Typical of the favourable student comments was: 'It's available anywhere even from home. It's very handy to study at your own speed.'

\section{Gender differences in the assessment results}

There are large differences in the mean assessment results between the genders as shown in Table 3. 
An interesting result, but perhaps outside the scope of this paper to explain, is that on average the women did better than the men. Women consistently scored better than men in both assignments, while in the final exam the scores were more equal.

We expected that the women would score more highly on the group 'research project' which involves communication, report-writing and teamwork. We expected that the "Webpage project', which is more technical, would favour the males. This turned out not to be the case, and in fact the females scored consistently better for both assignments, except in the summer school.

\begin{tabular}{|c|c|c|c|c|c|c|c|c|c|c|}
\hline \multirow[t]{2}{*}{$\overline{\text { All }}$} & \multirow[t]{2}{*}{ Semester } & \multirow{2}{*}{$\begin{array}{c}\text { No. } \\
\text { Students }\end{array}$} & \multicolumn{2}{|c|}{ Assl } & \multicolumn{2}{|c|}{ Ass2 } & \multicolumn{2}{|c|}{ Final } & \multicolumn{2}{|c|}{ Total } \\
\hline & & & Mean & NS & Mean & NS & Mean & NS & Mean & Pass Rate \\
\hline & Semester 1, 1999 & 71 & 62.4 & 0 & 60.3 & 0 & 65.9 & 4 & 61.5 & 87.3 \\
\hline & Semester 2, 1999 & 83 & 58.1 & 2 & 59.7 & 5 & 63.8 & 8 & 56.8 & 83.1 \\
\hline & Summer School & 25 & 59.1 & 0 & 59.1 & 1 & 61.1 & 4 & 54.7 & 76.0 \\
\hline & Semester 1, 2000 & 88 & 53.9 & 1 & 58.6 & 0 & 61.7 & 13 & 55.1 & 73.9 \\
\hline \multirow[t]{6}{*}{ Female } & Semester & No. & \multicolumn{2}{|c|}{ Assl } & \multicolumn{2}{|c|}{ Ass2 } & \multicolumn{2}{|c|}{ Final } & \multicolumn{2}{|c|}{ Total } \\
\hline & & Students & Mean & NS & Mean & NS & Mean & NS & Mean & Pass Rate \\
\hline & Semester I. 1999 & 21 & 70.4 & 0 & 65.5 & 0 & 68.4 & 0 & 67.6 & 95.2 \\
\hline & Semester 2, 1999 & 31 & 60.7 & 0 & 63.7 & 0 & 63.8 & 2 & 61.5 & 87.1 \\
\hline & Summer School & 7 & 64.1 & 0 & 57.6 & 0 & 49.1 & 0 & 55.1 & 85.7 \\
\hline & Semester I, 2000 & 22 & 64.0 & 0 & 60.0 & 0 & 60.7 & 4 & 56.7 & 72.7 \\
\hline \multirow[t]{6}{*}{ Male } & Semester & No. & \multicolumn{2}{|c|}{ Assl } & \multicolumn{2}{|c|}{ Ass2 } & \multicolumn{2}{|c|}{ Final } & \multicolumn{2}{|c|}{ Total } \\
\hline & & Students & Mean & NS & Mean & NS & Mean & NS & Mean & Pass Rate \\
\hline & Semester 1, 1999 & 50 & 59.1 & 0 & 58.1 & 0 & 64.8 & 4 & 58.9 & 84.0 \\
\hline & Semester 2, 1999 & 52 & 56.4 & 2 & 57.0 & 5 & 63.8 & 6 & 54.0 & 80.8 \\
\hline & Summer School & 18 & 57.2 & 0 & 59.7 & 1 & 67.2 & 4 & 54.6 & 72.2 \\
\hline & Semester 1,2000 & 66 & 50.4 & 1 & 58.2 & 0 & 62.0 & 9 & 54.6 & 74.2 \\
\hline
\end{tabular}

NS = Non-submission, Ass $1=$ Assignment I (group research report), Ass2 = Assignment 2 (Website project). Final = Final Exam

\section{Table 3: Mean assessment results 1999-2000 by gender}

This may be because the men are more likely to be over-confident, leave assignments to the last minute, and therefore score less well. Some supporting evidence for this comes from the non-submission results. The women always submitted every assignment, whereas the men were much more likely not to submit assignments. Further evidence comes from the selfassessment results. In Semester 1, 1999, of the twelve students who never recorded any quiz attempts, eleven were male and only one was female. Perhaps the women follow our instructions, while the men felt the quizzes were unnecessary for them.

\section{Remote'/class differences in the assessment results}

For both genders, who completed the course, the online learners did better than their classroom counterparts, although the differences are not significant. However, we do not attribute this to students learning better online. Instead it is more likely that the better students, with greater prior knowledge of the subject, or a better developed work ethic, tend to choose to work online. 
Belanger (1999) reports a study at York University, where students taking online courses achieved significantly higher grades. However there are just as many studies that report classroom students performing better. According to Kerlin, Hitz predicted in 1990 that 'there will be no significant difference in scores measuring mastery of material taught in the virtual and traditional classrooms'. And with the exception of 'computer science courses', in which the virtual class (VC) grades were significantly better, his research showed no significant differences. In an online computer science course at the University of Ulster, Anderson (1997) noted some improvement and certainly no deterioration in academic grades achieved compared with previous groups who studied in class.

\section{Gender differences in student access to the learning materials on the course Website}

The logfiles from WebCT show that on average women attempt more of the weekly selfassessment quizzes, view more pages of the course Website and read and post more bulletin board messages as shown in Tables 4 and 5 . The females' page views are consistently higher across the semesters than the males by a factor of 1.5 . The average number of bulletin board messages read by females is also more than the males by a factor of 1.7 in summer school, 1999-2000, and a factor of 2.3 in Semester 1, 2000.

\begin{tabular}{lcrrrrr}
\hline Semester & $\begin{array}{l}\text { Female } \\
\text { Hits }\end{array}$ & \multicolumn{1}{c}{ Read } & Posted & $\begin{array}{r}\text { Male } \\
\text { Hits }\end{array}$ & Read & Posted \\
\hline Semester 1, 1999 & \multicolumn{1}{c}{. } & - & - & - & - & - \\
Semester 2,1999 & 217.9 & 0.0 & 0.0 & 144.6 & 0.0 & 0.0 \\
Summer School, 1999-2000 & 498.9 & 120.3 & 5.0 & 342.8 & 68.7 & 3.9 \\
Semester 1, 2000 & 416.9 & 38.5 & 4.3 & 249.2 & 16.2 & 2.6 \\
\hline
\end{tabular}

Table 4: Average total semester WebCT page views and bulletin board access by gender

We tell the students that they must attempt the self-assessment quizzes every week, but many of them never attempt any of the quizzes. There is a wide spread of numbers of attempts ranging from none to all possible quizzes (the actual total number of possible quizzes is gradually increasing as we improve the course Website). The average number of unique attempts shows a consistent difference between the genders. The females, on average, attempt more quizzes than the males. The males are much more likely never to attempt any quizzes.

\begin{tabular}{lccccc}
\hline Semester & Total & \multicolumn{2}{c}{ Female } & \multicolumn{2}{c}{ Male } \\
& Quizzes & Average & Never & Average & Never \\
\hline Semester 1, 1999 & 16 & - & 1 & & 11 \\
Semester 2,1999 & 18 & 11.8 & 5 & 8.7 & 10 \\
Summer School, 1999-2000 & 18 & 12.7 & 1 & 11.6 & 1 \\
Semester 1,2000 & 20 & 11.4 & 4 & 7.4 & 20 \\
\hline
\end{tabular}

Never $=$ did not record any quiz attempts over the entire semester

Average $=$ Average total number of unique quiz attempts over the entire semester

Table 5: Average total weekly self-assessment question attempts by gender 
It seems as though the men are missing out on 'practice and drill' and this is reflected in their assessment results (see Table 3). Do the men think they know better and tend to ignore our instructions and go off and do their own thing, whereas women work methodically through our instructions and do everything asked of them?

\section{End of course questionnaire}

In the end of course questionnaire, one of the questions is: 'How useful was online learning for you?' It is hard to make any statistically viable conclusion from the results beyond the fact that on average the students rated their experiences of online learning very highly. However, there are two points to make. In Semester 1, 1999, the male students who studied remotely gave a much lower score than either their remote female counterparts or the males who studied in class, suggesting that they had a less positive experience. However, this trend did not continue in the following semesters. One reason for this may be that in Semester 1, 1999, the males had no experience of what online learning was about, whereas in later semesters they could draw on the experiences of the network of previous students. Furthermore, based on the results of the previous semester from Semester 2, 1999 onwards, we have explicitly warned the over-confident young males of the pitfalls of online learning, and sent out regular emails to remind them. Perhaps this group decided to study in class, or maybe they just have a more realistic attitude towards online learning.

\begin{tabular}{lcccccc}
\hline Semester & \multicolumn{3}{c}{ Female Average Rating } & \multicolumn{3}{c}{ Male Average Rating } \\
& Class & Remote & Maybe & Class & Remote & Maybe \\
\hline Semester 1, 1999 & 4.4 & 4.6 & 5.0 & 4.2 & 3.4 & 4.8 \\
Semester 2, 1999 & 3.9 & 4.4 & 5.0 & 4.2 & 4.3 & 5.0 \\
Summer School, 1999-2000 & - & 3.8 & - & - & 3.9 & - \\
Semester 1, 2000 & 4.6 & 4.3 & 4.0 & 4.0 & 4.6 & 5.0 \\
\hline
\end{tabular}

Table 6: How useful was online learning for you?

\section{Discussion}

Many authors note that limited computer resources can widen the gender gap in the classroom, as men literally push women off the computers (Spender, 1995: 187). In our practical sessions there is one computer for every student so this is a non-issue. However, we do notice that women tend to sit together in the practical sessions, so perhaps women are choosing to work remotely because they do find the environment of the maledominated computer classroom unsavoury.

So what about the boys? According to Bob Lingard (1998), of the University of Queensland, this refrain is an attempt to argue that masculinity is under siege and men are disadvantaged. Peter Zohrab (1999) echoes his concerns in New Zealand and claims that men are already being scared away from some professions. We feel that if there is to be a debate about the recuperative men's movement for learning or that girls are being shortchanged (Kleinfeld, 1998), it should focus on adjusting antisocial behaviour in the real or virtual classroom, thereby arresting the underachievement of a few of our youth.

Another reason why women may be more successful with online learning is that they set aside a weekly time to learn when interruptions will be kept to a minimum. When asked in 
focus groups 'when is the best time to be working online', our mature students tell us, 'late at night' or 'early in the morning', that is, when the family are not around and/or chores are completed. Conversely younger male students tell us they study 'any time'. In other words they do not plan quiet times, their login pattern is irregular with a shorter time-span and scattered frequency. Again, even in our in-class experience in this and other courses, we note that women tend to progress quietly through a set of linear instructions whilst the men jump ahead and are frequently in trouble.

Along with self-regulated task-focused learning, according to Corno and Mandinach (reported by Kohe), another attribute of online learning is 'resource management'. This is more relevant to the life experience of mature women, who, in their day-to-day organization of family matters, become adept at short-term management of events, which do not require extended mental effort. This type of management depends on family cooperation and the ability to juggle several smaller tasks within the same time frame. ${ }^{4}$ Could it be that women advantaged by this skill have the ability to develop cognitive flexibility in their learning styles? Has this 'training', necessary for dealing with small family crises, equipped them and some of our mature men to adapt to a piecemeal, event-interrupted regime of self-regulated learning? If mature people are more adept at resource management with background and foreground task-swopping, how can we transfer these skills to our younger male students who have not yet had the opportunity to develop such skills? As Campbell (1997) found, focus, motivation and time-management skills displayed by a number of her students equated with success for learning online. Lack of educational focus led to side-tracking.

We have found that the attributes for successful online learning include 'self-regulated learning' and being able to multi-task - dealing with interruptions and events then rescheduling as necessary. The student must then be able to re-focus quickly and continue working. The home environment as a learning space may not be conducive to this kind of scheduling. Self-regulated learning can be difficult when minor family emergencies occur.

A final reason that may also be influential on our course is the students' belief in their own performance. We record the students' belief about their ability to perform the tasks ahead online. The genders present a disparate picture regarding their perceived abilities to learn online. More young men believe that they have Internet and HTML experience than the women. In our first session we give everyone the opportunity to take part in the onlineonly course. Of the younger males (18-20) who choose this manner of learning, the majority are confident of their success. Like Selby et al. (1997) we have found that mature women who choose learning online do not exhibit the same confidence. We counsel the class to reflect on their learning styles and time-management skills, whilst reminding them that they can always contact us, or if they change their mind, attend on-campus sessions. The mature group is more self-effacing about their perceived skill-set and, as Kerlin suggests, this can be predicated by a large range of competencies or personal attributes that might include age, gender and ethnic background.

Most of our ethnic women and the majority of the mature ethnic males choose campusbased learning, whilst a number of mature New Zealand women choose online off-campus learning because of family commitments. The research of Margolis et al. (1998) indicates that, although the ethnic group they studied in Canada may suffer from dismay and loss of 
confidence about their perceived skills compared with the males in the class, they overcame this by tenacity and stayed in computing. Another theory could be that they do not display the English-language skill which allows their locally born female classmates to transfer to other disciplines. So they simply stay in IT through lack of choice as we have observed in the New Zealand environment. ${ }^{5}$

Should we filter out the over-confident students, take them aside and tell them that in our experience' their group has been less successful than their cohorts who are less confident but work harder? Should we insist that they become F2F learners? Or, do we supply extra tuition on how to 'learn successfully online'. In our opinion the first option is flawed because not all the young men need the extra help to become self-regulated learners. As we constantly strive to allow choice, we will keep a wary eye out for evidence of nonperformance and attempt to motivate and enthuse via feedback whilst offering extra tuition to prepare all our students for this new technology-assisted delivery.

\section{Conclusion}

Mature New Zealand women have the study skills necessary for learning online. The basic skills of self-regulation and time management would appear to be underdeveloped within the group of young males learning online. This is evidenced by non-performance in our online self-assessment quizzes, assessment results and site usage. The mature women who have these skills choose to work online because of convenience, flexibility and 'computing for a purpose'. There is evidence that for some learners the online system is complimentary rather than a replacement (Anderson, 1997; Richie, 1997).

This paper is a platform for discussion of the implications of online learning for both genders. There is a need for more research on who is more successful learning online, not only for marketing purposes but so that we, as online instructors, can facilitate the transfer of the necessary skills to all participants whatever their gender, age or ethnicity. The investment in hardware, software and time by both institution and learner is high enough to warrant research on who learns best and how everyone can benefit from this new teaching and learning approach.

\section{Acknowledgements}

Our thanks to all the IWD students. Dr Cathy Gunn of the University of Auckland conducted a focus group and provided useful suggestions. Professor Christopher Triggs of the University of Auckland provided statistical advice. Financial support was provided in the form of a grant from the Faculty of Business UNITEC Institute of Technology.

\section{Notes}

1 To gain an insight into the terminology of a technical wizard also known as a 'geek', visit the Website of self-styled 'early nerd' Peter Vogel, inventor and managing director of Righthemisphere at www.righthemisphere.com.

2 For example the University of Technology Sydney (UTS) currently promotes IT as a career for women using information packs for high school women, together with mentoring of school girls and undergraduates by IT career women. While as far back as 1988, Auckland Institute of Technology organized a competition for young female 
programmers according to Costain, G. (1999), 'Benefits of holding young women's programming contests', Living Science Conference.

3 While in the developed world there is more parity in the genders, there is still inequality in the third world. The many barriers to women's participation in online learning and communication are documented in a report by the Commonwealth of Learning, at http://www.col.org/barriers.htm.

4 Ellen Ullman (1997) describes this as a human way to echo the computer's time slice model - one task in the foreground the others in the background.

$s$ In the past three years New Zealand has experienced a huge increase in the number of Chinese, Taiwanese and Indian immigrants, most of whom end up in tertiary education whilst trying to gain employment.

\section{References}

Anderson, T. (1997), 'Integrating lectures and electronic course materials', Innovations in Education and Training International, 34 (1), 24-31.

Australian Information Industry Association, 'Women in information technology', http://www.aiia. comau/careers/careerwomen.html (accessed July 2000).

Bates, A. W. (1995), 'The impact of technological change on open and distance learning', Brisbane, Australia, 4-6 December 1996.

Bates, A. W. (1999), 'Strategies for the future', http://bates.estudies.ubc.calpaper2.html (accessed October 1999).

Belanger, M. (1999), 'The social impacts of information and communication technologies' (ICY), A Report prepared for the Schoolnet Program Industry, Ed-Media, Canada, 1999.

Bell, V. and de La Rue, D. (1995), 'Gender harassment on the Internet', Georgia State University College of Law, http://www.gsu.edu/ lawsand.papers/harass.html (accessed August 2000).

Blum, K. (1999), 'Gender differences in asynchronous learning in higher education', Journal of Asynchronous Learning Networks, 3 (1), 46-7.

Brook, P., Mann, S. and Virtue, A. (2000), 'Aberrant behaviour', Proceedings of the 13th Anmual Conference of the National Advisory Committee on Computing Qualifications (NACCQ) Conference, Wellington, New Zealand, 29-36.

Campbell, N., (1997), 'Online learning for pre-service teachers', Computers in NZ Schools, 21-4, http://www.waikato.ac.nzleducation/

Currie, D. (1993), 'The construction of gender at UBC Computing Services', University of British Columbia, http://www.herplace.org/compgend.html (accessed September 2000).

Dewstow, R., Young, S. and McSporran, M. (2000), 'Remote remedies: challenges when teaching online', Proceedings of the National Advisory Committee on Computing Qualifications Conference (NACCQ), Wellington, New Zealand.

eMarketer (4 April 1999), 'Women equal number of men online', http:/lemarketeer.com/ estats/040599_women.htm (accessed May 1999). 
Kleinfeld, J. (1998), 'The myth that schools shortchange girls: social science in the service of deception', http://www.uaf.edu/northern/schools/myth.html (accessed July 2000).

Kramarae, C. and Taylor, H. J. (1993), 'Women and men on electronic networks: a conversation or monologue?', in H. J. Taylor, C. Kramarae and M. Ebben (eds.), Women, Information Technology, and Scholarship, Center for Advanced Studies, University of Illinois, Urbana-Champaign.

Kerlin, B. A., 'Cognitive engagement style, self-regulated learning and cooperative learning', http://www.oit.pdx.edu/ kerlinb/myresearch/srl/self_reg_learn.html (accessed July 2000).

Lingard, B. (1998), 'Contextualising and utilising the "What about the boys?" backlash for gender equity goals', http://www.swin.edu.aulaare/98pap/lin98245.html (accessed July 2000).

Margolis, J., Fisher, A. and Miller, F. (1998), 'Geek mythology and attracting undergraduate women to computer sciences: closing the gender gap in higher education', Work in Progress for Carnegie Mellon Project on Gender and Computer Science, http://www.cs.emu.edu/ gendergap/working.html (accessed July 2000).

Margolis, J., Fisher, A. and Miller, F. (1999) 'Computing for a purpose: gender and attachment to computer science', Work in Progress for Carnegie Mellon Project on Gender and Computer Science, http://www.cs.emu.edu/ gendergap/ (accessed July 2000).

Richardson, H. and French, S. (1999), 'Gender and the cyber classroom', Unpublished Work in Progress: Information Systems Research Centre, University of Salford, M5 4WT, UK.

Ritchie, G. (1997), 'Online tutorials for electronic circuits - does it compare with traditional tutorials?', Proceedings of the 14th Annual Conference of the Australian Society for Computers in Learning in Tertiary Education (ASCILITE).

Selby, L., Ryba, K. and Young, A. (1997), 'Women in computing: what does the data show?', Proceedings of National Advisory Committee on Computing Qualifications (NACCQ) Conference, Nelson, New Zealand.

Simmons, J. (2000), personal comment, 'Blackboard Demonstration and Training Session', UNITEC, Auckland, 11 August 2000.

Spender, D. (1995), Nattering on the Net: Women Power and Cyberspace, Melbourne: Spinifex Press.

Trinkle, D. A. (1999), 'Distance education: a means to an end, no more, no less', http://www.onlinelearning.net/OLE/ChronicalArticle.html (accessed July 2000).

We, G. (1993), 'Cross-gender communication in cyberspace', Department of Communication, Simon Fraser University.

WebCT, Product Homepage, http://about.webct.com/ (accessed July 2000).

Ullman, E. (1997), 'A computer is not a metaphor', http:/lwww.salon. com/sept97/21st/tech4970911.html (accessed August 2000). 
Young, S., Dewstow, R. and McSporran, M. (1999). 'Who wants to learn online?', Proccedings of National Advisory Committee on Computing Qualifications (NACCQ) Confirence, Dunedin, New Zealand.

Zohrab, P. (1999), 'What about us? - Boys in schools and men in society', http:I/www.zohrab.orglboysnwsl.html (accessed July 2000). 